Vol. 19, 2011, pp. 8-14, DOI: 10.2478/v10228-011-0002-3

\title{
INFLUENCE OF HEAT INPUT ON THE CONTENT OF DELTA FERRITE IN THE STRUCTURE OF 304L STAINLESS STEEL GTA WELDED JOINTS
}

\author{
doc. Ing. Pavol SEJČ, PhD. ${ }^{1}$, Ing. Rastislav KUBÍČEK ${ }^{2}$ \\ Slovak University of Technology, Faculty of Mechanical Engineering
}

\begin{abstract}
Welding of austenitic stainless steel has its specific issues, even when the weldability is considered good. The main problems of austenitic stainless steel welding are connected with its metallurgical weldability. The amount of the components presented in the structure of stainless steel welded joint affect its properties, therefore the understanding of the behavior of stainless steel during its welding is important for successful processing and allows the fabricators the possibility to manage the resulting issues. This paper is focused on the influence of heat input on the structural changes in GTA welded joints of austenitic stainless steel designated: ASTM SA TP 304L.
\end{abstract}

KEYWORDS: GTA welding, Pulse Welding, Heat Input, Delta Ferrite Content, 304L Stainless Steel

\section{INTRODUCTION}

The amount of phase elements in the structure of an austenitic steel welded joint determines its properties, such as its mechanical properties, corrosion resistance or susceptibility to hot cracking. To prevent the formation of hot cracks, the delta ferrite content should be controlled in the range of $3 \div 12$ vol.\% $[1,2]$. Delta ferrite in the structure of stainless steel provides higher dissolvability of low melting phases compared to Austenite. A higher content of delta ferrite decreases the tendency of cracking during solidification, which is very important in the case of heating condition, which causes the formation of a polyedric structure which does not enable low melting point elements to be displaced to the surface of the weld by dendritical segregation [3]. Different GTA welding variations (e.g. manual/automatic GTAW; with/without the use of filler material) produce different cooling and solidification rates and provide a certain range of heat input. In the case of 304L austenitic steel joints welded by different variations of GTAW method, the whole heat input range provides the conditions for the formation of the structure with a certain content of polyedric structure. Due to the above mentioned aspects, the delta ferrite content needs to be controlled with an aim to achieve the properties of the joint to be suitable for specific applications.

\section{EXPERIMENT}

Sample joints for the experiment have been prepared in the scope to represent the mentioned heat input range and to determine its influence on the content of delta ferrite in the structure of welded joints in AISI 304L plate with 2,0 $\mathrm{mm}$ thickness. For the production of joint samples, the following GTA welding modes have been used:

- Manual GTAW using filler material; in pulse and continual mode

- Manual GTAW without the use of filler material; in pulse and continual mode 
Vol. 19, 2011, pp. 8-14, DOI: 10.2478/v10228-011-0002-3

- Automatic GTAW without the use of filler material; in pulse and continual mode For the performance of joint samples, the following materials have been used:

1. Base material with the designation ASTM A $240 \mathrm{TP} 304 \mathrm{~L}$ in the form of a plate with 2,0 mm thickness.

2. Filler material with the designation AWS/SFA A5.9 ER 308L.

Filler material has been selected in order to achieve approximately equal chemical composition of weld metal to the base material to provide approximately equal $\mathrm{Cr}$ and $\mathrm{Ni}$ and to affect the rate of ferrite and austenite to a minimum range in the final structure of the weld metal. Chemical composition (based on attest 3.1 according to EN 10204) of both base and filler material and $\mathrm{Cr} / \mathrm{Ni}$ equivalents are calculated according to following formula:

$\mathrm{Cr}_{\mathrm{EK}}=\% \mathrm{Cr}+\% \mathrm{Mo}+1,5 \% \mathrm{Si}+0,5 \mathrm{x} \% \mathrm{Nb} ; \mathrm{NI}_{\mathrm{EK}}=\% \mathrm{Ni}+30 \mathrm{x} \% \mathrm{C}+0,5 \mathrm{xMn}$,

are included in tab.1.

\begin{tabular}{|c|c|c|c|c|c|c|c|c|}
\hline Material & \multicolumn{6}{|c|}{ Chemical composition [\%] } & $\mathrm{Cr}_{\mathrm{EK}}$ & $\mathbf{N i}_{\text {EK }}$ \\
\hline \multirow{2}{*}{ 304L } & $\mathrm{Cr}$ & & & Mn & $\mathrm{Si}$ & $\mathbf{C}$ & \multirow{2}{*}{19,2} & \multirow{2}{*}{11,2} \\
\hline & 19 & & & 2 & 1 & 0,03 & & \\
\hline \multirow[t]{2}{*}{ ER 308L } & $\mathrm{Cr}$ & $\mathbf{N i}$ & Mn & Si & $\mathrm{C}$ & Mo & \multirow{2}{*}{20,0} & \multirow{2}{*}{12} \\
\hline & 19,29 & 10,38 & 1,96 & 0,33 & 0,022 & 0,21 & & \\
\hline
\end{tabular}

Tab.1 Chemical composition of base and filler material

\section{PREPARATION OF JOINT SAMPLES AND DETERMINATION OF WELDING CONDITIONS}

Joint samples have been prepared by GTAW method of welding (141 according to STN EN 24063) of material SA TP 304L in the form of 2,0 mm thickness plate without beveled edges. In order to ensure proper backing protection, a $\mathrm{Cu}$ backplate with a groove for backing gas flow has been used. Welding conditions and parameters have been proposed to comply with the requirements of visual testing according to EN ISO 5817, class B [4] and requirements on the geometry and purity to achieve the joints to be suitable for direct contact with foods and liquids.

Tab. 2 documents the visual appearance of the selected weld joint samples, cross section macrostructure images and the used welding parameters. Evaluation of the weld joint samples has been focused on the following subjects:

A. Determination of the influence of heat input/GTA welding mode on amount of delta ferrite present in the heat affected zone

B. Determination of the content of the structural elements in weld metal in dependence on the heat input/welding mode

C. Determination of the influence of heat input/welding mode on the amount of delta ferrite present in the heat affected zone

Determination of delta ferrite content has been realized by the microscopic analysis supported by measurements using the graphical method. Heat input has been calculated on the basis of EN 1011-1: 


$$
Q=\eta \frac{U . I .60}{v_{Z V}}\left[\mathrm{~kJ} . \mathrm{cm}^{-1}\right],
$$

where: U - Voltage on the arc, I - Welding current, $\mathrm{v}_{\mathrm{zV}}$ - Welding travel speed, $\mu$ - Coefficient of efficiency for GTAW is 0,6 . [5]

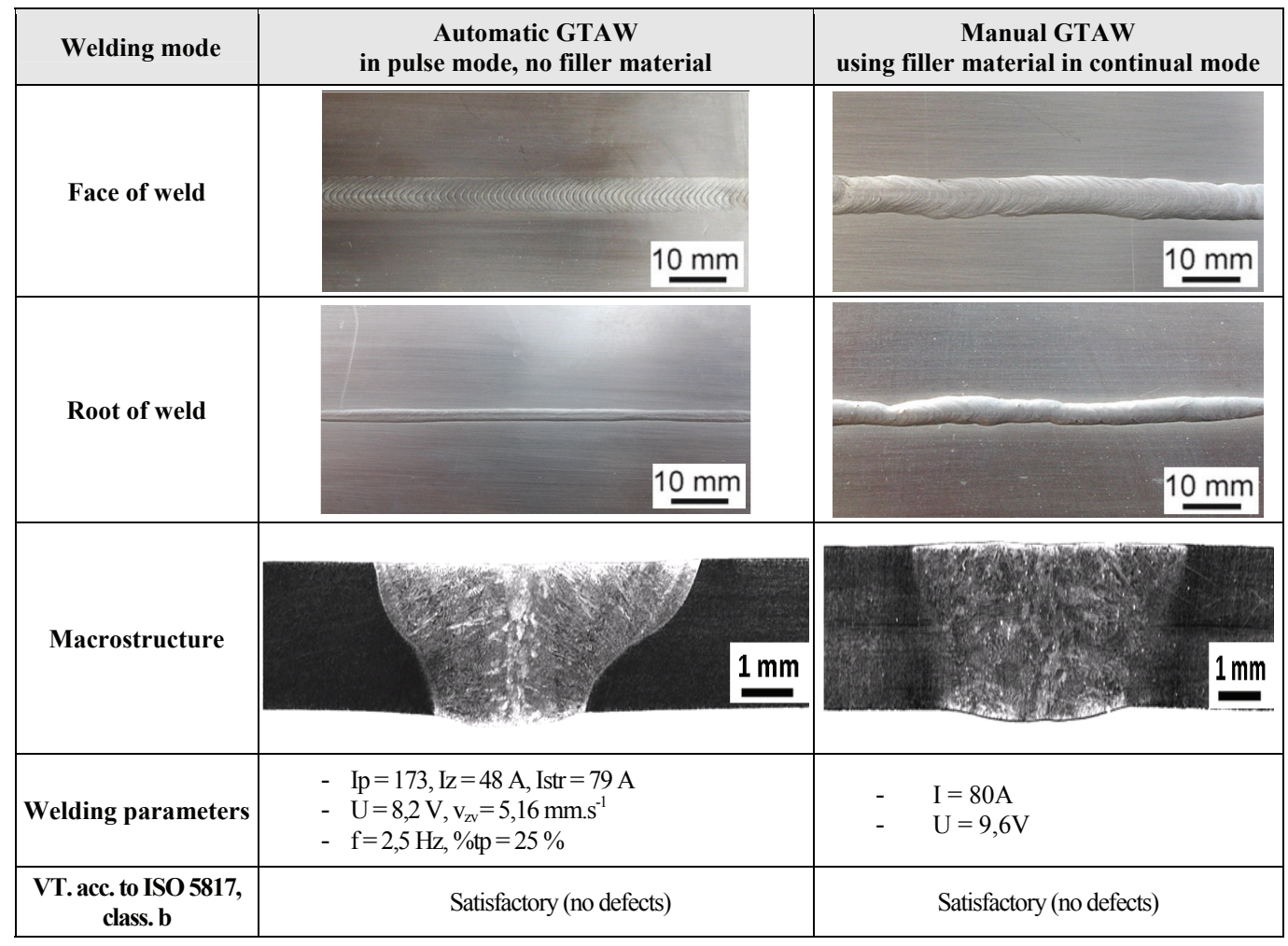

Tab.2 Welds performed by automatic and manual GTAW; visual appearance of face and root of weld; cross section macrostructure images; welding parameters used

Additional welding variables used are included in Tab. 3 .

\begin{tabular}{|l|l|l|l|}
\hline Variable & Value of variable & Type of variable & Value of variable \\
\hline Welding position & PA (STN ISO 6947) & Electricity mode & Pusle/continual \\
\hline Shield gas & $\mathrm{Ar} 99,996 \%(\mathrm{EN} 439 / 11)$ & Electrical current type / polarity & DC/EN \\
\hline Shield gas flow rate & $151 / \mathrm{min}$ & Welding technique & Leftside \\
\hline Backing gas & $90 \% \mathrm{~N}_{2} / 10 \% \mathrm{H}_{2}$ & Number of layers & Singlelayer \\
\hline Backing gas flow rate & $101 / \mathrm{min}$ & Oscilation & No $(\mathrm{string}$ bead) \\
\hline $\begin{array}{l}\text { Tungsteen electrode } \\
\text { type/diameter }\end{array}$ & $\mathrm{WP} / 2,0 \mathrm{~mm}$ & Length of tack welds & $\begin{array}{l}1=3 . \mathrm{s}[\mathrm{mm}], \mathrm{s}=\text { base mat. } \\
\text { thickness }\end{array}$ \\
\hline Tungsteen electrode & $4 \mathrm{~mm} / 35^{\circ}$ angle & Tack welds pitch & $\mathrm{e}=30 . \mathrm{s}[\mathrm{mm}], \mathrm{s}=$ base mat. \\
\hline
\end{tabular}


Vol. 19, 2011, pp. 8-14, DOI: 10.2478/v10228-011-0002-3

\begin{tabular}{|l|l|l|l|}
\hline extension/angle & & & thickness \\
\hline
\end{tabular}

Tab.3 Additional welding variables

After review and comparison of the cross section microscopic images, a certain amount of delta ferrite present in the heat affected zone has been observed. In order to determine its amount and obtain the most accurate values, measurement has been carried out using the following methods:

1. Measuring the width of delta ferrite zone presented in heat affected zone (fig. 1)

2. Measuring the area of delta ferrite presented in the heat affected zone

1. Weld samples have been prepared for microstructure analysis using the standard microstructure procedure. Microstructure analysis and measurements have been carried out using the stereo optical microscope Olympus GX 51. Measuring has been performed in three different locations as the thermal load in the reference to the thickness of weld is non-uniform. On the basis of the microstructure images, it can be concluded, that higher thermal energy is concentrated into the root of the weld, therefore the root zones show different amounts of delta ferrite. Measurement location no.2. and no.0 (fig.1) have been placed $300 \mu \mathrm{m}$ from the weld surface (measurement location no.2) and $300 \mu \mathrm{m}$ form the weld root surface (measurement location no.0). Isotherm transition line A has been assigned exactly to the place of transition between the weld metal and heat affected zone, at 1000x magnification. At the same magnification, isotherm line $\mathrm{B}$ has been assigned to the place representing the average distance of delta ferrite presence. Width of the delta ferrite has been measured between assigned isotherm lines A. and B. (fig. 1) Measurement has been carried out on the joint samples performed using all the proposed welding modes in order to determine the influence of various heat inputs on the structural changes in the heat affected zone.

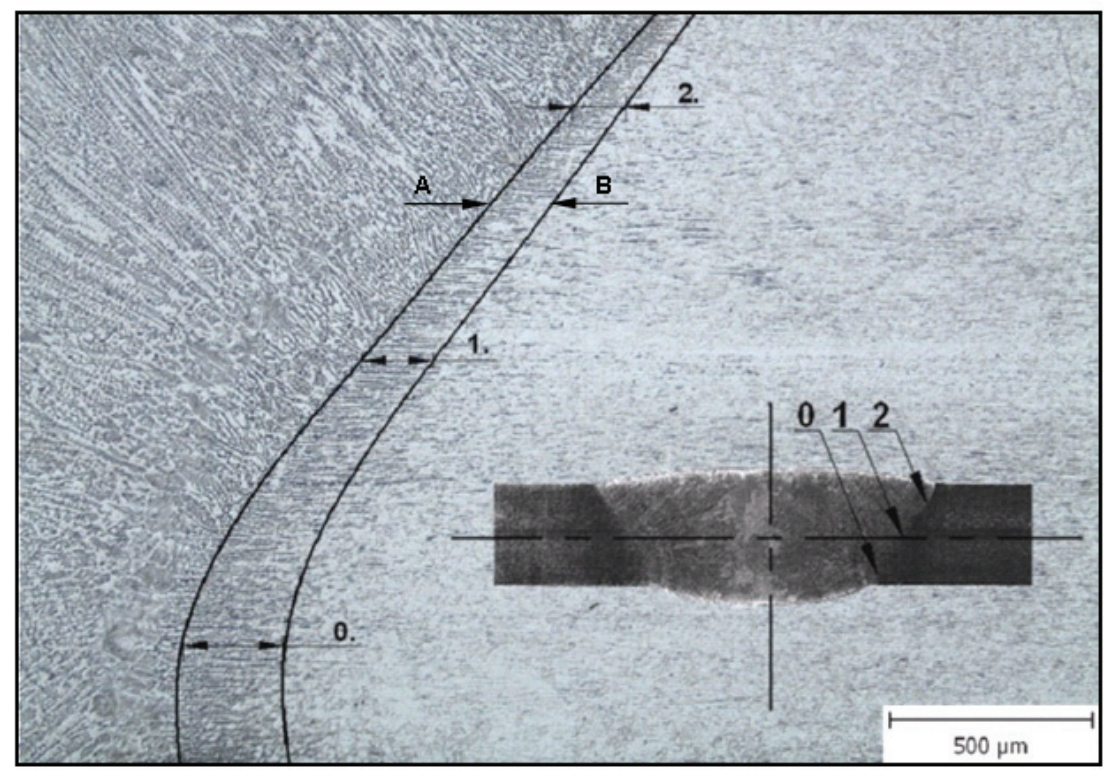


Vol. 19, 2011, pp. 8-14, DOI: 10.2478/v10228-011-0002-3

Fig. 1 Measuring procedure of delta ferrite presented in the heat affected zone

2. Measuring has been performed on the same joint samples as have been used for the measurement of the delta ferrite width, as well as the area of a delta ferrite formation in the heat affected zone has been specified using the same procedure as has been used for the measurement of the delta ferrite width. After the area of delta ferrite has been defined, it is measured using the graphical method and automatically calculated by the software program calculation.

\section{A. Determination of the content of elements in the structure of weld metal in dependence} to the heat input/GTA welding mode

This Measurement has been carried out using the graphical method by software Mediacybernetics Image-Pro, intended for structural analysis. Images have been taken from three different locations of the weld metal in order to represent the entire weld metal structure. In order to achieve the highest measurement accuracy, the program has been set to the highest sensitivity of pixel selection. Delta ferrite in the vermicular form and austenite has been automatically detected by the program. Afterwards, the percentual content of phases has been automatically calculated. Measurement has been applied for the joint samples performed by the proposed GTA welding modes in order to determine the influence of various heat input range on the structural changes in the weld metal.

\section{CONCLUSION}

After the review and comparison of microstructure images of sample joints performed at different heat inputs, certain amounts of delta ferrite have been possible to visually detect beginning from the transition of base material - heat affected zone and continuing to the heat affected zone, were its amount and distance from the base material - heat affected zone transition is a function of the heat input. Fig. 2 documents the comparison of cross sectional microstructure images of weld joints performed by different GTA welding modes. It is visually possible to detect higher amounts of delta ferrite present in the heat affected zone on the samples performed by the GTA welding using the mode which provides higher heat input (such as manual GTAW using filler material in continual current mode) compared to weld joints performed using GTA welding in the mode providing lower heat input, such as automatic GTAW or automatic GTAW in pulse current mode.

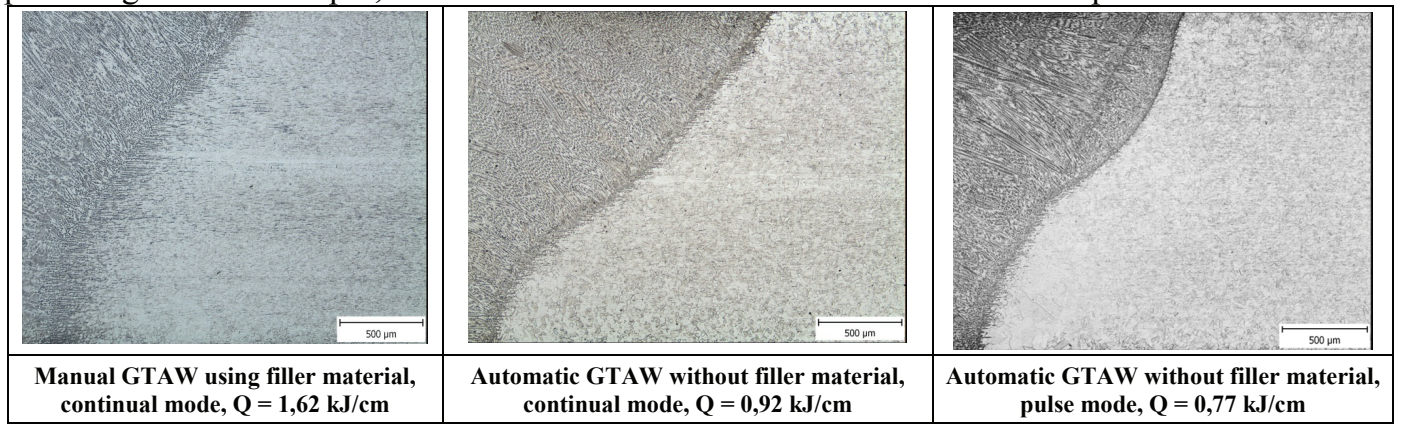

Fig.2 Comparison of microstructure images, weld samples performed at different heat input values. 
Vol. 19, 2011, pp. 8-14, DOI: 10.2478/v10228-011-0002-3

\section{Measuring the width of delta ferrite presented in heat affected zone}

Measurements of delta ferrite in the structure of the heat affected zone have confirmed that the amount of delta ferrite presented in the structure of heat affected zone is a function of the heat input. Measured width values ranged from $18 \mu \mathrm{m}$ (joint performed by the automatic pulse GTAW mode at heat input $\mathrm{Q}=0,77 \mathrm{~kJ} / \mathrm{cm}$ ) to $307 \mu \mathrm{m}$ (joint performed by the manual GTAW using filler material at a heat input $\mathrm{Q}=1,62 \mathrm{~kJ} / \mathrm{cm}$ ). Influence of welding heat input on the delta ferrite amount is presented in the diagram on fig. 3 .

\section{Measuring the area of delta ferrite presence in heat affected zone}

Results of delta ferrite area measurements (fig. 4) correspond to the results of width measurements (fig. 3) and confirm the effect of the heat input on the delta ferrite presence. Lower heat input (representing automatic pulse GTA welding) causes the lowest presence of delta ferrite, which has been measured in the value of $0,05 \mathrm{~mm}^{2}$, while the highest area $-0,54 \mathrm{~mm}^{2}$ has been measured on the sample welded by manual welding mode with higher welding heat input.

\section{A. Presence of delta ferrite in the structure of the weld metal}

Measurement results of delta ferrite content in the structure of the weld metal have shown that increasing the heat input impacts the delta ferrite content (fig. 5). The highest value of delta ferrite content in the structure of the weld metal measured was 20,6\% (represents an automatic pulse GTAW at the heat input $\mathrm{Q}=0,77 \mathrm{~kJ} / \mathrm{cm}$ ), while the lowest value $10,7 \%$ has been measured in the joint performed by manual GTAW welding using a filler material in continuous current mode at the heat input $\mathrm{Q}=1,62 \mathrm{~kJ} / \mathrm{cm}$.

Measurement results have shown that increasing the heat input consequently causes the content of delta ferrite to increase in the heat affected zone, and simultaneously causes the decrease of delta ferrite in the structure of the weld metal. On the basis of the results, measured values have been presented in fig. 6 which shows the structural changes in the weld metal and heat affected zone of 304L welded joints of the dependence on heat input. In terms of weld joint properties, the point of intersection (green circle) determines the combination which provides an optimal solution. In the case of the susceptibility to solidification cracking in weld metal, it is preferable to apply the GTA welding mode providing lower weld heat input such as automatic pulse GTAW, which enables the formation of weld metal structure with a higher content of delta ferrite causing a better dissolving of low melting elements. In the case of liquation cracking in the heat affected zone, it is preferable to use the GTA welding mode providing higher heat input such as manual GTAW welding in continual current mode. Analogically it is possible to consider welding parameters and conditions in order to increase mechanical properties or atmospheric corrosion resistance and increase the total quality of the weld. The diagram is applicable for the stainless steels ASTM SA TP 304L in the form of plate of 2,0 mm thickness as well as for others of 300 series stainless steels (e.g. 304, 304L, 304H, 316) whose crystallization and phase transformation is analogous [6]. 


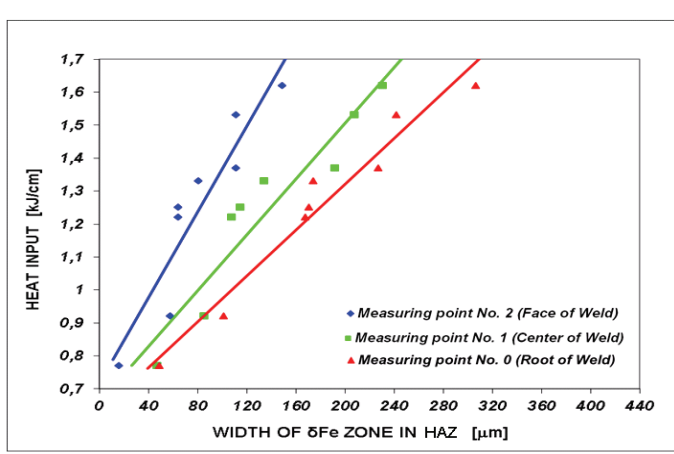

Fig. 3 Influence of the welding heat input on the width of delta ferrite zone present in the heat affected zone (HAZ); values included are averages of the left and right heat affected zone

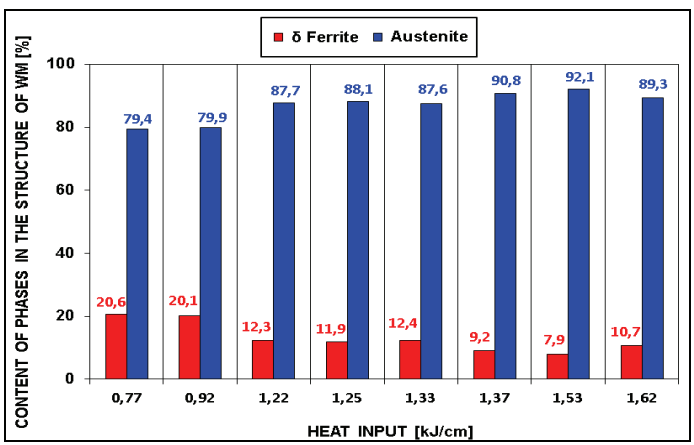

Fig. 5 Delta ferrite content in the structure of weld metal (WM) in dependence on the heat input

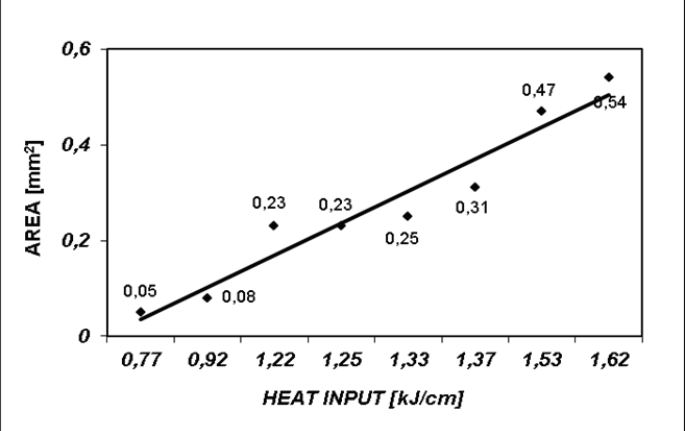

Fig. 4 Content of delta Fe formed in the heat affected zone in the dependence on the heat input

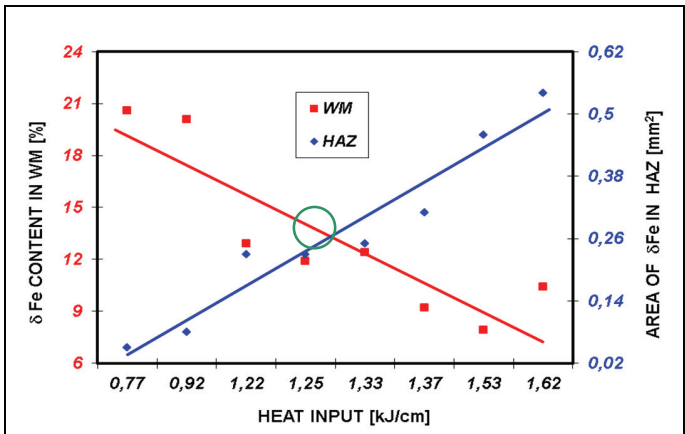

Fig. 6 Amount of delta ferrite $(\delta F e)$ in the structure of weld metal (WM) and heat affected zone (HAZ) in the dependence on the welding heat input

\section{REFERENCES}

[1] BRZIAK, P., PIUSSI, V., BERNASOVSKÝ, P., et al.: Materiály a ich správanie sa pri zváraní. Bratislava: VÚZ, 2003, 355s.

[2] CASTRO, R., J.J. De CADENET,: Welding Metallurgy of Stainless and Heat resisting Steels, Cambridge University Press, Cambridge, 1974. ISBN 052120431

[3] HRIVŇÁK, I.,: Zvaritel'nost' ocelí. Bratislava: Alfa, 1979, 235s. ISBN 80-224-0016-5

[4] EN ISO 5847 - Welding - Fusion-welded joints in steel,nickel, titanium and their alloys (beam welding excluded) - Quality levels for imperfections

[5] EN 1011-1, Welding. Recommendations for welding of metallic materials. General guidance for arc welding.

[6] LIPPOLD, C. J,. KOTECKY, D.,: Welding Metallurgy and Weldability of Stainless Steels. Wiley Interscience, 2005.353p. ISBN 0-471-47379-0 